\title{
A combined experimental and theoretical study of the tautomeric and conformational properties of (5-phenyl-tetrazol-2-yl)-acetic acid methyl ester
}

\author{
Aamer Saeed $^{\mathrm{a}, *}$, Muhammad Qasim ${ }^{\mathrm{a}}$, Majid Hussain ${ }^{\mathrm{a}}$, Ulrich Flörke ${ }^{\mathrm{b}}$, Mauricio F. Erben ${ }^{\mathrm{c}, *}$ \\ ${ }^{a}$ Department of Chemistry, Quaid-I-Azam University, Islamabad 45320, Pakistan \\ ${ }^{\mathrm{b}}$ Department Chemie, Fakultät fur Naturwissenschaften, Universitat Paderborn, Warburgerstrasse 100, D-33098 Paderborn, Germany \\ ${ }^{\mathrm{C}}$ CEQUINOR (UNLP, CONICET-CCT La Plata), Departamento de Química, Facultad de Ciencias Exactas, Universidad Nacional de La Plata, C.C. 962,1900 La Plata, Argentina
}

\section{H I G H L I G H T S}

- X-ray crystal structure was determined for novel tetrazole species.

- Electronic delocalization interactions are promoted by the nitrogen lone pair.

- Two conformations are almost isoenergetic, depending on the orientation of the $\mathrm{C}=\mathrm{O}$ with respect to the tetrazole ring.

- The tetrazol-2-tautomer is more stable than the tetrazol-1-form

- Vibrational properties are investigated.

\section{A R T I C L E I N F O}

\section{Article history:}

Received 13 February 2015

Received in revised form 13 May 2015

Accepted 15 May 2015

Available online 21 May 2015

\section{Keywords:}

Tetrazole

Vibrational spectroscopy

Quantum chemical calculations

Crystal structure

Conformational analysis

Tautomerism
G R A P H I C A L A B S T R A C T

(5-Phenyl-tetrazol-2-yl)-acetic acid methyl ester

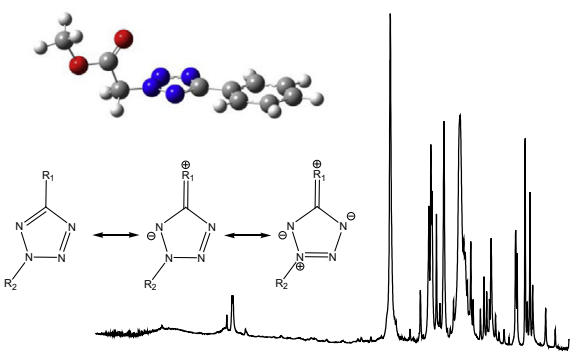

A B S T R A C T

The tautomeric and conformational properties of a new tetrazole derivative are studied in a combined approach that includes the analysis of the experimental vibrational data together with theoretical calculation methods, especially in terms of natural bond orbital (NBO) population analysis. Moreover, the molecular and crystal structure was determined by single crystal X-ray diffraction. The compound crystallized as the 2-tautomeric form, monoclinic space group $\mathrm{P} 22_{1} / \mathrm{c}$ with $Z=4, a=10.0630(14)$, $b=8.2879(11), c=12.8375(18) \AA, \beta=105.546(3)^{\circ}, V=1031.5(2) \AA^{3}$. The tetrazole and phenyl rings are coplanar with the acetate group oriented perpendicular to the plane. The NBO analysis showed that delocalizing interactions of the $\operatorname{lp}_{\mathrm{p}}(\mathrm{N} 2)$ lone pair orbital contributes to a strong resonance interactions with both adjacent $\pi^{*}(\mathrm{~N} 3=\mathrm{N} 4)$ and $\pi^{*}(\mathrm{~N} 1=\mathrm{C} 5)$ antibonding orbitals of the tetrazole group.

(C) 2015 Elsevier B.V. All rights reserved.

\section{Introduction}

Tetrazoles are a class of synthetic heterocycles with a wide range of applications in organic chemistry [1], coordination chemistry [2], the photographic industry and medicinal chemistry [3], as

* Corresponding authors. Tel.: +92 519064 2128; fax: +92 5190642241 (A Saeed). Tel./fax: +54 2214259485 (M.F. Erben).

E-mail addresses: aamersaeed@yahoo.com (A. Saeed), erben@quimica.unlp.edu. ar (M.F. Erben). well as activators in oligonucleotide synthesis [4]. The 5 -substituted tetrazoles are the non-classical bioisosteres of carboxylic acids [5], possessing similar acidities but higher lipophilicities and metabolic resistance [6]. In addition, the 5-phenyltetrazoles are known to exhibit several biological activities including antibacterial, antifungal [7], antinociceptive [8], analgesic and anti-inflammatory [9], anticonvulsant [10], hypoglycemic [11], and antihypertensive activities [12].

The thermal decomposition of tetrazole has also gained attention [13] mostly with the development of high-energy 


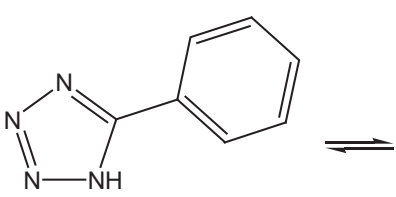

(1a)<smiles>c1ccc(-c2nn[nH]n2)cc1</smiles>

(1b)

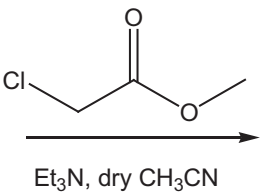

$\mathrm{Et}_{3} \mathrm{~N}$, dry $\mathrm{CH}_{3} \mathrm{CN}$

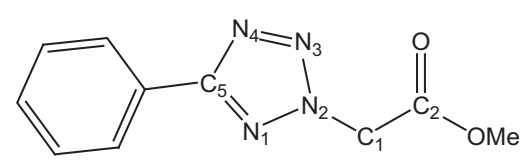

(2)

Scheme 1. Synthetic route of the title compound. Relevant atom numbering is also defined.

tetrazole-based compounds as potential explosive materials, electric igniters and solid rocket propellant formulations [14]. The explosive properties of tetrazoles are related to their molecular and electronic structure, the ranking in explosive behavior of 5-substituted tetrazoles correlates with the electron withdrawing capacity of the substituents [15].

From the structural point of view, it is well-known that the tetrazole cycle exists in two tautomeric forms, differing by position of the hydrogen atom [16]. Experimental techniques [17-19] and theoretical approaches [20-22] were applied to the study of this equilibrium. Further 1- and 2-substitution of the tetrazole hydrogen by organic group is also feasible, giving access to a variety of 1 - and 2-substituted tetrazole species.

In this work a new derivative was synthesized by the base catalyzed esterification of 5-phenyl-2H-1,2,3,4-tetrazole (1) with methyl 2-chloroacetate (Scheme 1), using the reaction conditions established earlier [23]. The precursor compound (1) as well as $\mathrm{N}$-(R-aminoalkyl)tetrazoles are known to exist in solution as equilibrium mixtures of N1 (1a) and N2 (1b) tautomers. The position of equilibrium depends considerably on the polarity of the solvent and the nature of substituents on the tetrazole ring. The use of triethylamine and acetonitrile followed by recrystallization from $n$-hexane exclusively affords a single pure tautomer [24]. Thus, following this procedure, the hitherto unknown (5-phenyl-tetrazol-2-yl)-acetic acid methyl ester (2) species has been prepared.

The crystal structure and vibrational properties were determined by single crystal X-ray diffraction and infrared spectroscopy complemented by quantum chemical calculations at the B3LYP/6-311++G(d,p) level of approximation. Moreover, the natural bond orbital (NBO) population analyses were determined to understand the effect of electronic interactions in the structural and conformational properties of the tetrazole moiety.

\section{Experimental}

Synthesis of (5-phenyl-tetrazol-2-yl)-acetic acid methyl ester

A mixture of 5-phenyltetrazole $(3 \mathrm{mmol})$, triethylamine (12 mmol) and acetonitrile $(25 \mathrm{~mL})$ was added dropwise to a stirred solution of methyl chloroacetate $(6 \mathrm{mmol})$ in $15 \mathrm{~mL}$ of acetonitrile. The reaction mixture was heated in an oil bath for $2 \mathrm{~h}$ keeping the temperature at $82^{\circ} \mathrm{C}$. The progress of the reaction was monitored by TLC. Acetonitrile was removed under reduced pressure and product was re-crystallized in $n$-hexane to get pure (5-phenyl-tetrazol-2-yl)-acetic acid methyl ester as a white crystalline solid (yield: $73 \%$ ). mp. $98-100{ }^{\circ} \mathrm{C}$. IR (Neat) $\mathrm{cm}^{-1}: 1281$ $(\mathrm{N}=\mathrm{N}-\mathrm{N}), 1547(\mathrm{Ar}-\mathrm{C}=\mathrm{C}), 1606(\mathrm{C}=\mathrm{N}), 1756(\mathrm{C}=\mathrm{O}), 2854\left(\mathrm{CH}_{3}\right)$,
3067 (Ar-C-H); ${ }^{1} \mathrm{H}$ NMR (300 MHz, DMSO) $\delta$ (ppm): 3.75 (s, 2H, $\left.\mathrm{CH}_{3}\right), 5.93\left(\mathrm{~s}, 2 \mathrm{H}, \mathrm{CH}_{2}\right), 7.57\left(\mathrm{~m}, 3 \mathrm{H}, \mathrm{Ar}-\mathrm{H}_{m, p}\right), 8.08(\mathrm{~m}, 2 \mathrm{H}, \mathrm{Ar}-$ $\left.\mathrm{H}_{o}\right) \cdot{ }^{13} \mathrm{C}$ NMR (75 MHz, DMSO) $\delta(\mathrm{ppm}): 53.43,53.83\left(\mathrm{CH}_{2} \mathrm{C}=\mathrm{O}\right.$, $\left.\mathrm{OCH}_{3}\right), 126.8\left(1^{\prime} \mathrm{C}\right), 127.0\left(2^{\prime} \mathrm{C}\right), 129.8\left(3^{\prime} \mathrm{C}\right), 131.3\left(4^{\prime} \mathrm{C}\right), 164.9$ (tetrazole ring carbon), $167.1(\mathrm{C}=0)$.

The precursor 5-phenyl tetrazole was prepared according to the literature procedure [6] (yield: 78\%). mp $216^{\circ} \mathrm{C}$ (lit. [6] $217^{\circ} \mathrm{C}$ ). ${ }^{1} \mathrm{H}$ NMR (300 MHz, DMSO) $\delta$ (ppm): 7.59-7.62 (m, 3H, Ar-H), 8.02$8.06(\mathrm{~m}, 2 \mathrm{H}, \mathrm{Ar}-\mathrm{H}),{ }^{13} \mathrm{C}$ NMR (75 MHz, DMSO) $\delta(\mathrm{ppm}): 124.6$ $\left(1^{\prime} \mathrm{C}\right), 127.2\left(2^{\prime} \mathrm{C}\right), 129.9\left(3^{\prime} \mathrm{C}\right) 131.7\left(4^{\prime} \mathrm{C}\right), 155.8$ (tetrazole ring carbon).

\section{Crystal structure determination}

Colorless crystal, size $0.37 \times 0.22 \times 0.20 \mathrm{~mm}^{3}$, monoclinic space group $\mathrm{P} 22_{1} / \mathrm{c}$ with $Z=4, \quad a=10.0630(14), \quad b=8.2879(11), \quad c=$ 12.8375(18) $\AA, \beta=105.546(3)^{\circ}, V=1031.5(2) \AA^{3} ; D_{\mathrm{c}}=1.405 \mathrm{Mg} / \mathrm{m}^{3}$, $\mu=0.103 \mathrm{~mm}^{-1}, F(000)=456$. The intensity data were recorded using a Bruker SMART CCD area-detector diffractometer with graphite monochromated $\mathrm{MoK}_{\alpha}$ radiation $(\lambda=0.71073 \AA)$ at $T=130(2)$ K. 9446 reflections collected $2.1>\Theta>27.9^{\circ} ; 2466$ independent reflections $I>2 \sigma(I)$. Structure solution by direct method full-matrix least squares refinement [25] based on $F^{2}$ and 146 parameters. All but H-atoms were refined anisotropically, hydrogen atoms were clearly located from difference Fourier maps, refined at idealized positions riding on the carbon or nitrogen atoms with isotropic displacement parameters $U_{\text {iso }}(\mathrm{H})=1.2 U_{\mathrm{eq}}(\mathrm{C})$ or $1.5 U_{\text {eq }}\left(\mathrm{C}_{\text {methyl }}\right)$ and $\mathrm{C}-\mathrm{H}$ 0.95-0.99 A. Refinement converged at $\mathrm{R} 1=0.039[I>2 \sigma(I)], \mathrm{WR} 2=0.100$ [all data] and $S=1.049 ; \mathrm{min} /-$ $\max \Delta F-0.20 / 0.27 \mathrm{e} / \AA^{3}$.

Crystallographic data (excluding structure factors) for the structure reported in this paper have been deposited with the Cambridge Crystallographic Data Centre as supplementary publication No. CCDC-1015473. Copies of available material can be obtained free of charge via www.ccdc.cam.ac.uk/data_request/cif, by e-mailing data_request@ccdc.cam.ac.uk, or contacting the Cambridge Crystallographic Data Centre, 12, Union Road, Cambridge CB2 1EZ, UK; fax: +44 1223 336033. Crystal data, structure refinements and geometrical parameters are given as Supplementary material.

\section{Instrumentation}

Melting point was determined using a digital Gallenkamp (SANYO) model MPDBM3.5 apparatus and is uncorrected. ${ }^{1} \mathrm{H}$ NMR and ${ }^{13} \mathrm{C}$ NMR spectra were determined in $\mathrm{CDCl}_{3}$ with a $300 \mathrm{MHz}$ Bruker AM-300 spectrophotometer. Mass Spectra (EI, $70 \mathrm{eV}$ ) were taken on a GC-MS, Agilent technologies $6890 \mathrm{~N}$ with 
an inert mass selective detector 5973 mass spectrometer and elemental analyses were conducted using a LECO-183 CHNS analyzer.

\section{Vibrational spectroscopy}

Solid-phase (in $\mathrm{KBr}$ pellets) infrared spectra were recorded with a resolution of $2 \mathrm{~cm}^{-1}$ in the $4000-400 \mathrm{~cm}^{-1}$ range on a Bruker EQUINOX 55 FTIR spectrometer. FTIR spectrum of the neat solid in the ATR mode was also recorded on a Bio-Rad-Excalibur Series Mode FTS 3000 MX spectrophotometer.

\section{Computational details}

Molecular quantum chemical calculations have been performed with the GAUSSIAN 03 program package [26] by using the B3LYP DFT hybrid methods employing Pople-type basis set [27]. The moderate $6-31+G(d, p)$ basis set has been applied for the relaxed scan calculations, whereas the extended valence triple- $\xi$ basis set augmented with diffuse and polarization functions in both the hydrogen and weighty atoms $[6-311++G(d, p)]$ has been used for geometry optimization and frequency calculations, as suggested by Saglam et al. for related tetrazole species [28]. The calculated vibrational properties corresponded in all cases to potential energy minima for which no imaginary frequency was found. The recommended scale factor of 0.96 has been applied for analyzing the theoretical harmonic vibrational frequencies [29]. Natural population analysis and second-order donor $\rightarrow$ acceptor interaction energies were estimated at the $\mathrm{B} 3 \mathrm{LYP} / 6-311++\mathrm{G}(\mathrm{d}, \mathrm{p})$ level by using the NBO analysis [30] as implemented in the GAUSSIAN 03 program.

\section{Tautomerism and conformational landscape}

Wierzejewska et al. have recently reported the molecular structure and the matrix infrared spectra for the related (tetrazol-5-yl)acetic acid, showing that the $1 H \rightarrow 2 H$ tautomerization equilibrium takes place, even when high energy barrier are predicted for the unimolecular tautomerization process [31,32]. In the present case, tautomeric equilibrium is precluded by substitution of the hydrogen atom from the tetrazole ring, but substitution at both 1 - and 2-positions can in principle take place during the synthesis procedure. Following the early work by Fraser et al., our ${ }^{1} \mathrm{H}$ NMR data (vide supra) suggest that the 2-position of the 5-phenyltetrazole ring is substituted [18]. The deshielding effect showed by the ortho protons (located at $8.08 \mathrm{ppm}$ ) is in accordance with the co-planarity of two aromatic rings which is sterically allowed, while in case of substitution at 1-position of 5-phenyltetrazole the ortho-protons are shielded. In order to shed more light on this aspect, the geometry and relative stability of both tautomers have been determined by using quantum chemical calculations. To further inspect the potential energy surface of the 1 - and 2-substituted tautomers, the potential energy function for internal rotation around the $\mathrm{C} 1-\mathrm{C} 2$ dihedral angles have been calculated. The B3LYP/6-31+G(d) level of approximation has been applied allowing geometry optimizations with the corresponding dihedral angle varying from $0^{\circ}$ to $360^{\circ}$ in steps of $10^{\circ}$. The potential energy curve is shown in Fig. 1.

When the potential energy curve obtained for the 2-tautomer is analyzed, nearly equivalent minima are observed for the syn $\left[\delta(\mathrm{O} 1=\mathrm{C} 2-\mathrm{C} 1 \mathrm{~N} 2) \mathrm{ca} .10^{\circ}\right]$ and anti $\left[\delta(\mathrm{O} 1=\mathrm{C} 2-\mathrm{C} 1 \mathrm{~N} 2) \mathrm{ca} .190^{\circ}\right]$ conformers, the energy difference being almost negligible. In both structures, the tetrazole and phenyl groups are co-planar, the $\mathrm{C}(\mathrm{O}) \mathrm{O}$ - ester group oriented perpendicular to this plane. Contrary to this conformational behavior, it is worth noting that for (tetrazol-5-yl)acetic acid, the $-\mathrm{C}(\mathrm{O}) \mathrm{O}-$ group is nearly co-planar with the tetrazole ring [31]. It is plausible that the

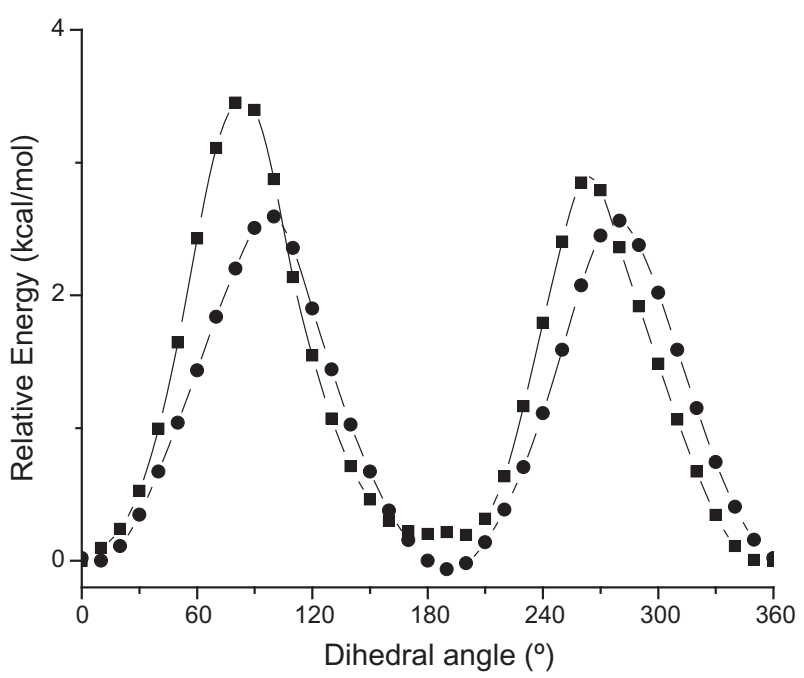

Fig. 1. Calculated $[B 3 L Y P / 6-31+G(d, p)]$ potential function for internal rotation around the $\delta(\mathrm{O} 1=\mathrm{C} 2-\mathrm{C} 1 \mathrm{~N} 2)$ dihedral angle for the $1(-\mathbf{-}-)$ and $2\left(-\mathbf{-}_{-}\right)$tautomers of the title compound. For atom numbering see Scheme 1.

$\mathrm{C}=\mathrm{O} \cdots \mathrm{H}-\mathrm{N}$ intramolecular hydrogen bond between the carboxylic group and the $1-H$ tetrazole moiety favors the planar conformation.

For the 1-tautomer both, the syn and anti conformations are also located at minima in the potential energy surface, the syn form being slightly preferred. Higher torsional barriers are calculated for the 1-tautomer, especially for the structure with $\delta(\mathrm{O} 1=\mathrm{C} 2-\mathrm{C} 1 \mathrm{~N} 2)$ ca $80^{\circ}$, probably because to steric interactions raised when the $\mathrm{C}=\mathrm{O}$ group point toward the phenyl group.

Additionally, full geometry optimizations and frequency calculations were computed for the two main tautomeric forms in their syn and anti conformations by using the B3LYP functional and the more extended $6-311++G(d, p)$ basis set. The relative electronic energies (corrected by zero point energy) computed for each form is given in Fig. 2. The 2-syn form is more stable than the 1-syn form by $6.11 \mathrm{kcal} / \mathrm{mol}$ ( $\Delta E^{\circ}$ values, including zero point energy) for the molecule isolated in a vacuum. The syn and anti conformers have nearly the same energy, independently of the tautomeric form under consideration. Moreover, the obtained geometrical parameters and vibrational data will be discussed in the following sections.

\section{Molecular and crystal structure}

Fig. 3 shows the X-ray molecular structure of methyl 2-(5-phenyl-1H-tetrazole-1-yl)acetate and Table 1 summarizes the main geometric parameters. In good agreement with the structure obtained by quantum chemical calculations, the phenyl and the tetrazole rings are almost co-planar with a dihedral angle of $3.89(8)^{\circ}$ between the two planes. The plane of the acetate group is perpendicular to the tetrazole moiety with relevant torsion angles N3-N2-C1-C2 89.9(2) ${ }^{\circ}$ and $\mathrm{O} 1=\mathrm{C} 2-\mathrm{C} 1 \mathrm{~N} 219.2(2)^{\circ}$.

The methyl acetate group displays the usual syn conformation, with 01-C2-O2-C3 4.5(2) ${ }^{\circ}$ [33]. Somewhat related molecular structures are those of 1-phenyl-3-(5-phenyl-2H-tetrazol-2-yl)bu tan-1-one [34] or 5-phenyl-2-p-tolyl-2H-tetrazole [35].

As already noted for 5 [36] and 2-substituted species [37], the formal double bonds are strongly delocalized in the planar tetrazole ring and the alternation of single and double bonds is scarcely noted. The bond length and bond are similar to that reported for other tetrazoles substituted in position 2 [37]. In the present case, the $\mathrm{N}-\mathrm{N}$ bond distances are in the range 1.31-1.33 $\AA$, with the N2N3 and N3N4 and bond lengths being identical [1.315(2) and 


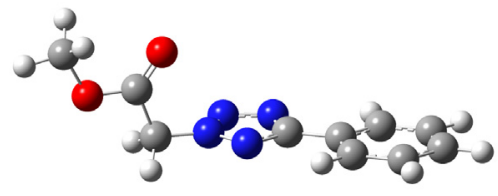

2-syn (0.00)

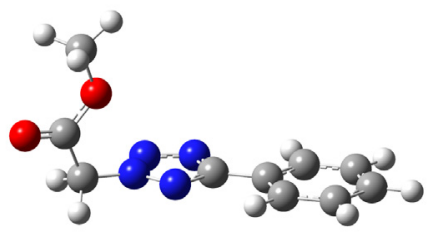

2-anti (0.04)

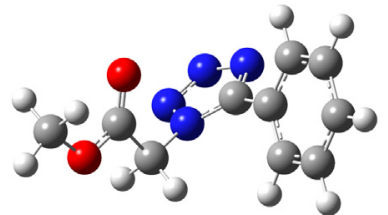

1 -syn (6.11)

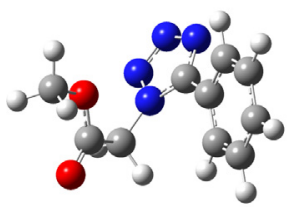

$1-\operatorname{anti}(6.46)$

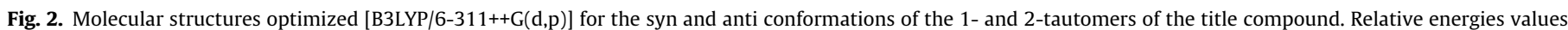
$\left(\Delta E^{\circ}\right.$, in $\left.\mathrm{kcal} / \mathrm{mol}\right)$ are given $\left(E^{\circ}=-756.512031\right.$ Hartrees for the most stable 1 -syn form $)$.

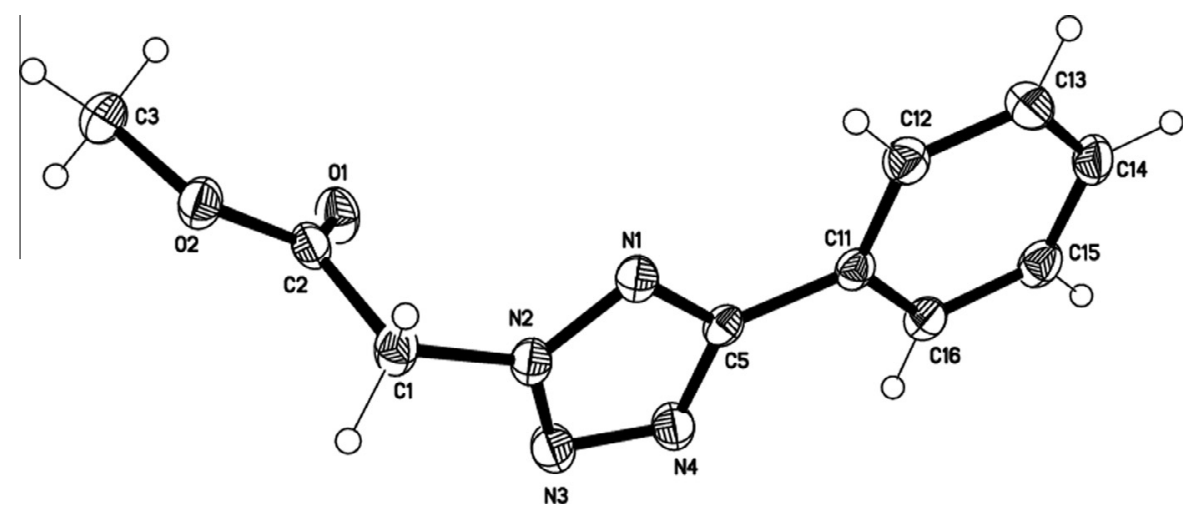

Fig. 3. Molecular structure of the title compound with anisotropic displacement ellipsoids drawn at the 50\% probability level.

Table 1

Selected bond distances $(\AA)$ and bond angles $\left(^{\circ}\right)$ for the title compound.

\begin{tabular}{|c|c|c|c|c|c|c|c|}
\hline Bond lengths & N1-N2 & N1-C5 & $\mathrm{C} 5-\mathrm{N} 4$ & $\mathrm{C} 5-\mathrm{C} 11$ & N2-N3 & N3-N4 & $\mathrm{N} 2-\mathrm{C} 1$ \\
\hline X-ray & $1.330(1)$ & $1.332(2)$ & $1.354(2)$ & $1.469(2)$ & $1.315(2)$ & $1.318(2)$ & $1.446(2)$ \\
\hline Computed & 1.302 & 1.364 & 1.332 & 1.466 & 1.330 & 1.327 & 1.444 \\
\hline Bond angles & N1C5N4 & N4C5C11 & N3N2C1 & N3N4C5 & $\mathrm{C} 5 \mathrm{~N} 1 \mathrm{~N} 2$ & N3N2N1 & N4N3N2 \\
\hline X-ray & $112.1(1)$ & $123.9(1)$ & $122.4(2)$ & $106.2(1)$ & $101.3(2)$ & $114.4(1)$ & $106.0(1)$ \\
\hline Computed & 111.4 & 124.0 & 122.7 & 123.4 & 101.9 & 113.8 & 106.1 \\
\hline
\end{tabular}

$1.318(2) \AA ̊$, and the N1N2 slightly longer [1.330(2) $\AA$ ] as gathered in Table 1 . The molecular structure obtained with quantum chemical calculations at the B3LYP/6-311++G(d,p) fails in reproducing this tendency, predicting large N1N2 and N2N3 (ca. $1.33 \AA$ ) bonds and a shorter N3N4 (1.30 ̊) distance. The exocyclic angles at the $\mathrm{N} 2\left[122.4(2)^{\circ}\right.$ and $\left.123.1(2)^{\circ}\right]$ and $\mathrm{C} 5\left[123.9(1)^{\circ}\right]$ atoms indicate that steric repulsion between 2 - and 5-substitution are absent.

The crystal packing of the title compound is shown in Fig. 4. Intermolecular $\mathrm{C} 3-\mathrm{H} 3 \mathrm{C} . \mathrm{N} 3(-x+1,-y,-z+1)$ interactions with H...N $2.59 \AA$ and $\mathrm{C}-\mathrm{H} . . \mathrm{N} 129^{\circ}$ that link molecules into centro-symmetric dimers that are stacked along [010].

\section{Vibrational analysis}

The FTIR (see Fig. 5A) and ATR (see Fig. S5 in the Supplementary material) spectra for the title species in the solid phase have been measured. The nearly identical features obtained when these spectra are compared give confidence in the vibrational analysis. Experimental and calculated [B3LYP/6-311++G(d,p)] frequencies and intensities are given in Table 2 and the simulated spectrum is shown in Fig. 5B. A tentative assignment of the observed bands was carried out by evaluation of the computed spectra, as well as on comparison with spectra of related molecules. In particular, the infrared spectra of the "parent" tetrazole species in the solid state and isolated in an argon matrix were studied by Fausto et al. [38], clearly showing that the $1-H$ tautomer is the predominant form. The vibrational spectra of the related tetrazole acetic acid species have been reported independently by Fausto [39] and Wierzejewska [32]. In $1-H$ and $2-H$ 5-substituted tetrazoles, the assignment of the normal mode of vibrations associated with the motion of the ring coordinates is a difficult task since they are usually strongly coupled. In the present case, it should be noted 


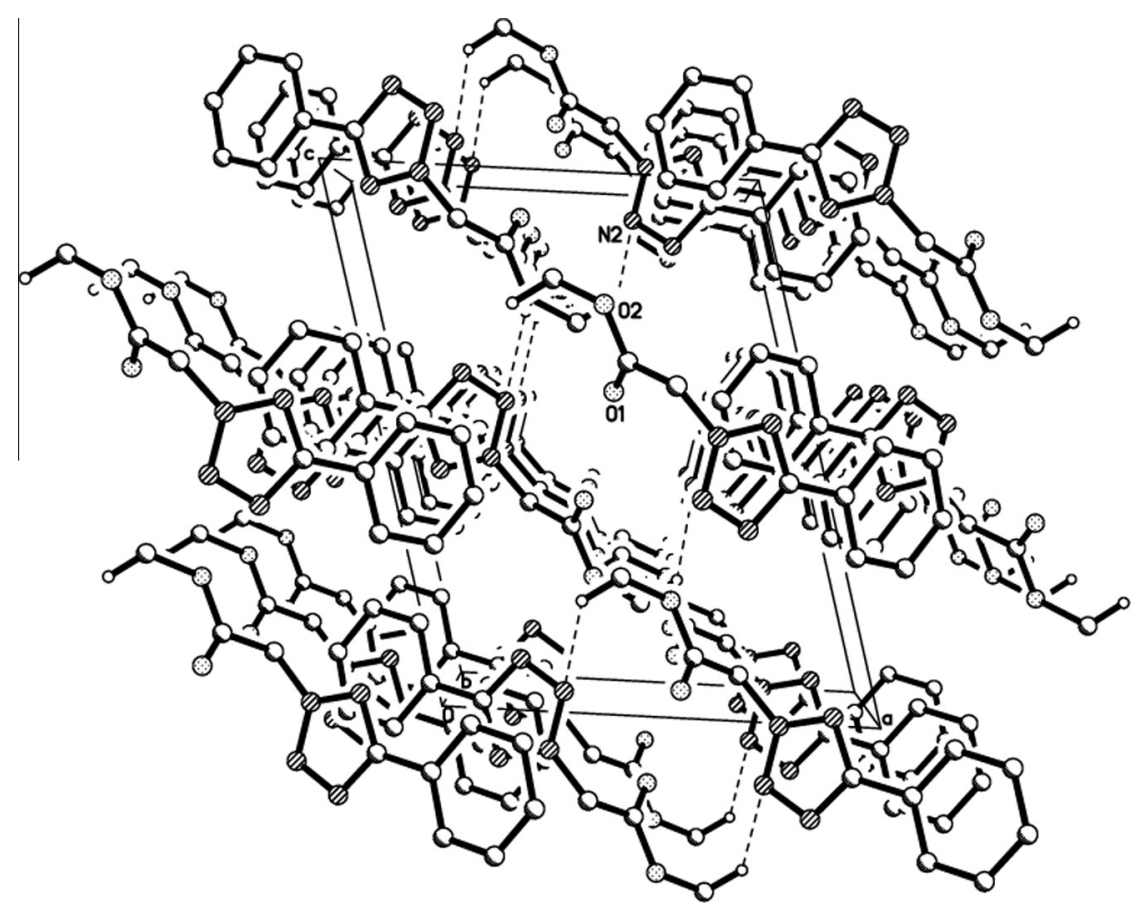

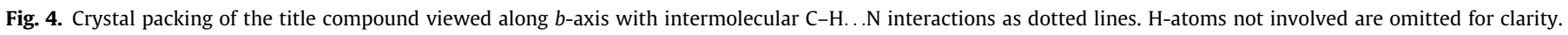

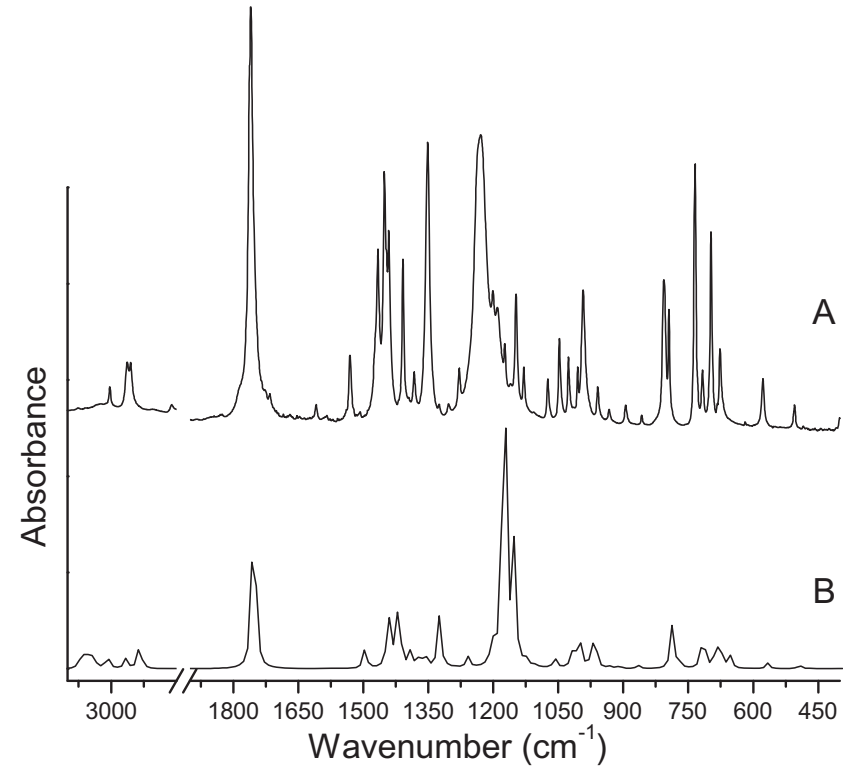

Fig. 5. (A) Infrared (in $\mathrm{KBr}$ pellet) spectrum for the solid phase of the title species. (B) Simulated infrared spectrum from frequency calculations at the B3LYP/6$311++G(d, f)$ level of approximation.

that very similar infrared spectra are computed for both tautomeric forms, as showed in Table 2.

The nitrogen-nitrogen stretching modes $[v(\mathrm{NN})]$ are responsible for absorptions of medium intensity appearing at 1408, 1148 and $1060 \mathrm{~cm}^{-1}$, tentatively assigned to the $\mathrm{v}(\mathrm{N} 1=\mathrm{N} 2) / \mathrm{v}(\mathrm{C} 5=\mathrm{N} 4)$, $v(\mathrm{~N} 2 \mathrm{~N} 3)$, and $v_{\mathrm{s}}(\mathrm{N} 1 \mathrm{~N} 2 \mathrm{~N} 3)$, in good agreement with previous studies [28]. The deformation modes involving the ring coordinates appears in the infrared spectrum at 1026 and $806 \mathrm{~cm}^{-1}$, mainly associated with the $\delta(\mathrm{NC} 5 \mathrm{~N})$ and $\delta(\mathrm{NNN})$ deformations, respectively.

The characteristic vibration of the ester group, the $v(C=0)$ and $v(\mathrm{C} 2 \mathrm{O} 2)$ stretching modes are observed as intense absorptions at
1760 and $1229 \mathrm{~cm}^{-1}$, in perfect agreement that reported for the tetrazole acetic acid species, at 1761 and $1199 \mathrm{~cm}^{-1}$ [32,39]. Subtle differences are computed for these normal modes between the 2-syn and 2-anti conformers. Thus, the $\mathrm{v}(\mathrm{C}=\mathrm{O})$ modes is expected at higher frequencies for the 2-syn form, the computed shift amounting to $25 \mathrm{~cm}^{-1}$. On the other hand, the $v(\mathrm{C} 2 \mathrm{O} 2)$ mode appears at higher frequencies $\left(61 \mathrm{~cm}^{-1}\right)$ for the 1 -syn form. It is difficult to determine if the occurrence of conformational equilibrium is responsible for the broad features associated with the bands at 1760 and $1229 \mathrm{~cm}^{-1}$, as observed in Fig. 5 .

The mode of vibrations associated with the phenyl, methyl and methylene groups are within the usual values, as listed in Table 2.

\section{NBO analysis}

NBO analysis was performed mainly to study the influence of electronic delocalization on the tautomeric and conformational preference and on the geometry of the tetrazole fragment. The results for the 2-tautomer in its syn and anti conformation clearly indicates the presence of lone pair orbitals formally centered at each of the nitrogen atoms of the tetrazole group. However, while a pure p-type $\left[\operatorname{lp}_{\mathrm{p}}(\mathrm{N} 2)\right]$ described the lone pair attached to the N2 nitrogen atom, $\mathrm{s}-\mathrm{p}$ hybrid-type lone pairs with $\sigma$ symmetry are found for the other nitrogen atoms. The $\mathrm{lp}_{\mathrm{p}}(\mathrm{N} 2)$ displays the lowest electron occupancy, 1.48 e, indicating the electron-donating capacity for this orbital. On the other hand, the electronic occupancy of the other nitrogen of the tetrazole ring are much higher, amounting to 1.93 (N4), 1.95 (N3) and 1.94 (N1) e. The atomic charges obtained using the natural population analysis approach (NPA) reveal that the tetrazole nitrogens are negatively charged, from -0.018 (N2) up to -0.274 (N1), while the $\mathrm{C} 5$ bear a strong positive charge $(+0.310)$, denoting the contribution of the double excited resonance structure proposed by Oziminski and Krygowski for the 2-H-tetrazole [40] (Scheme 2).

Delocalizing interactions evaluated by a second-order perturbation approach reveals that the $\operatorname{lp}_{\mathrm{p}}(\mathrm{N} 2)$ lone pair orbital contributes to a strong resonance interactions with both adjacent $\pi^{*}(\mathrm{~N} 3=\mathrm{N} 4)$ 
Table 2

FTIR and FT-ATR experimental data for the title compounds, together with the computed B3LYP/6-311++G(d,p) values and tentative normal mode assignment.

\begin{tabular}{|c|c|c|c|c|c|}
\hline \multirow[t]{2}{*}{ FTIR $^{\mathrm{a}}$} & \multirow[t]{2}{*}{ ATR } & \multicolumn{3}{|c|}{ B3LYP/6-311++G(d,p) } & \multirow[t]{2}{*}{ Tentative assignment } \\
\hline & & 2-Syn & 2-Anti & 1-Syn & \\
\hline 3003vvw & $3003 w$ & $3201(3.4)$ & $3201(3.9)$ & $3204(2.0)$ & $v(\mathrm{C}-\mathrm{H})\left(\mathrm{C}_{6} \mathrm{H}_{5}\right)$ \\
\hline 2963w & $2960 w$ & $3197(6.0)$ & $3196(5.9)$ & 3192 (11.9) & \\
\hline 2955w & $2955 m$ & 3186 (18.9) & $3186(17.7)$ & 3183 (15.9) & \\
\hline \multirow[t]{7}{*}{ 2862vvw } & $2862 w$ & 3175 (11.5) & $3175(11.0)$ & $3173(2.8)$ & \\
\hline & $2811 w$ & $3166(11.1)$ & $3169(7.4)$ & $3167(10.0)$ & $\mathrm{V}_{\mathrm{s}}(\mathrm{C}-\mathrm{H})\left(\mathrm{CH}_{3}\right)$ \\
\hline & & $3165(0.03)$ & $3165(0.09)$ & $3165(3.2)$ & $v(\mathrm{C}-\mathrm{H})\left(\mathrm{C}_{6} \mathrm{H}_{5}\right)$ \\
\hline & & $3141(0.8)$ & $3145(1.1)$ & $3140(0.3)$ & $v_{\mathrm{as}}(\mathrm{C}-\mathrm{H})\left(\mathrm{CH}_{2}\right)$ \\
\hline & & $3133(14.0)$ & 3135 (13.1) & 3134 (13.9) & $v_{\mathrm{as}}(\mathrm{C}-\mathrm{H})\left(\mathrm{CH}_{3}\right)$ \\
\hline & & 3089 (10.7) & $3093(8.7)$ & $3094(8.9)$ & $v_{s}(\mathrm{C}-\mathrm{H})\left(\mathrm{CH}_{2}\right)$ \\
\hline & & $3057(29.1)$ & $3058(25.8)$ & $3057(26.1)$ & $v_{\mathrm{s}}(\mathrm{C}-\mathrm{H})\left(\mathrm{CH}_{3}\right)$ \\
\hline \multirow[t]{2}{*}{ 1760vs } & $1757 v s$ & $1826(210.9)$ & $1801(380.2)$ & 1821 (197.9) & $v(C=0)$ \\
\hline & $1716 \mathrm{sh}$ & & & & \\
\hline \multirow[t]{2}{*}{-} & - & $1648(0.4)$ & $1648(0.3)$ & $1648(0.4)$ & $v(C=C)$ \\
\hline & & $1622(0.2)$ & $1622(0.2)$ & $1619(1.0)$ & \\
\hline \multirow[t]{3}{*}{$1531 \mathrm{br}, \mathrm{w}$} & $1541 w$ & $1558(22.6)$ & $1558(22.4)$ & 1567 (12.7) & $v(\mathrm{C} 1-\mathrm{C} 2)$ \\
\hline & $1531 w$ & $1502(52.2)$ & $1502(53.7)$ & $1505(32.2)$ & $\delta(\mathrm{C}-\mathrm{H})\left(\mathrm{C}_{6} \mathrm{H}_{5}\right)$ \\
\hline & & $1497(13.5)$ & $1495(8.1)$ & $1497(9.9)$ & $\delta_{\mathrm{as}}\left(\mathrm{CH}_{3}\right)$ \\
\hline \multirow[t]{3}{*}{$1467, \mathrm{~m}$} & $1467 \mathrm{~m}$ & $1484(10.9)$ & $1484(10.2)$ & 1485 (38.9) & $\delta\left(\mathrm{CH}_{3}\right)$ \\
\hline & & $1474(50.2)$ & $1479(52.3)$ & $1485(10.9)$ & $\delta(\mathrm{C}-\mathrm{H})\left(\mathrm{C}_{6} \mathrm{H}_{5}\right)$ \\
\hline & & $1471(13.1)$ & $1473(11.7)$ & $1472(12.2)$ & $\delta_{\mathrm{s}}\left(\mathrm{CH}_{3}\right)$ \\
\hline \multirow[t]{2}{*}{$1449 \mathrm{~s}$} & 1449s & $1448(19.1)$ & $1447(8.2)$ & $1455(22.6)$ & $\delta_{\mathrm{s}}\left(\mathrm{CH}_{2}\right)$ \\
\hline & & $1426(14.2)$ & $1420(24.9)$ & $1437(29.3)$ & $v(\mathrm{C} 1-\mathrm{N} 2)$ \\
\hline $1408 \mathrm{~m}$ & $1407 \mathrm{~m}$ & $1412(11.7)$ & $1408(15.8)$ & $1356(16.6)$ & $v(\mathrm{~N} 4=\mathrm{N} 3)$ \\
\hline $1351 \mathrm{~s}$ & $1350 s$ & 1379 (58.7) & $1362(6.8)$ & $1386(41.7)$ & $\delta_{\mathrm{as}}\left(\mathrm{CH}_{2}\right)$ \\
\hline $1325 \mathrm{vw}$ & & $1358(1.5)$ & $1356(2.2)$ & $1354(2.2)$ & $\rho(\mathrm{C}-\mathrm{H})\left(\mathrm{C}_{6} \mathrm{H}_{5}\right)$ \\
\hline \multirow[t]{2}{*}{$1304 v w$} & & $1339(0.6)$ & $1341(6.9)$ & $1324(2.8)$ & $\delta_{\mathrm{as}}\left(\mathrm{CH}_{2}\right)$ \\
\hline & & $1310(12.0)$ & $1312(22.3)$ & $1295(13.2)$ & $v(C=C)$ \\
\hline $1278 w$ & $1278 \mathrm{~m}$ & $1252(26.0)$ & 1250 (34.9) & $1281(3.0)$ & $v_{a s}(\mathrm{NC} 5 \mathrm{~N})$ \\
\hline $1229 v s, b r$ & $1226 v s$ & $1224(397.4)$ & $1285(287.4)$ & $1226(377.7)$ & $v(\mathrm{C} 2-\mathrm{O} 2)$ \\
\hline $1201 \mathrm{~m}, \mathrm{sh}$ & $1201 \mathrm{~m}, \mathrm{sh}$ & $1202(5.5)$ & $1208(2.4)$ & $1204(0.6)$ & $\rho(\mathrm{C}-\mathrm{H})\left(\mathrm{C}_{6} \mathrm{H}_{5}\right)$ \\
\hline $1191 \mathrm{~m}, \mathrm{sh}$ & $1190 \mathrm{~m}, \mathrm{sh}$ & $1200(127.4)$ & $1201(4.0)$ & $1202(91.5)$ & $\rho_{\mathrm{as}}\left(\mathrm{CH}_{3}\right)$ \\
\hline \multirow[t]{3}{*}{$1173 \mathrm{~m}, \mathrm{sh}$} & $1174 w, s h$ & $1183(0.07)$ & $1183(0.1)$ & $1185(0.08)$ & $\rho(C-H)\left(C_{6} H_{5}\right)$ \\
\hline & & $1172(3.1)$ & $1174(1.3)$ & $1171(0.8)$ & $\rho_{\mathrm{as}}\left(\mathrm{CH}_{3}\right)$ \\
\hline & & $1169(4.3)$ & $1170(6.0)$ & $1138(10.7)$ & $\rho s\left(\mathrm{CH}_{3}\right)$ \\
\hline $1148 \mathrm{~m}$ & $1147 \mathrm{~m}$ & 1151 (1.9) & $1154(0.2)$ & 1125 (23.9) & $v(\mathrm{~N} 2-\mathrm{N} 1)$ \\
\hline $1130 w$ & $1130 w$ & $1101(10.4)$ & $1102(9.4)$ & $1102(9.8)$ & $\rho(\mathrm{C}-\mathrm{H})\left(\mathrm{C}_{6} \mathrm{H}_{5}\right)$ \\
\hline $1075 \mathrm{~m}$ & $1073 \mathrm{~m}$ & $1060(15.6)$ & $1060(14.0)$ & $1058(2.2)$ & $v(\mathrm{~N} 2-\mathrm{N} 3)$ \\
\hline $1047 \mathrm{~m}$ & $1047 \mathrm{~m}$ & 1044 (40.9) & $1043(36.4)$ & $1034(7.7)$ & $v(C=C)$ \\
\hline $1026 \mathrm{~m}$ & $1026 \mathrm{~m}$ & $1022(3.4)$ & $1026(55.7)$ & $1017(3.1)$ & $\delta(\mathrm{NC} 5 \mathrm{~N})$ \\
\hline $1005 w$ & $1005 w$ & $1016(0.7)$ & $1022(7.3)$ & $1015(4.1)$ & $\delta(\mathrm{CCC})$ \\
\hline \multirow[t]{2}{*}{$993 \mathrm{~s}$} & $992 \mathrm{~m}$ & $1006(43.1)$ & $1016(0.5)$ & $1009(0.02)$ & $v\left(\mathrm{H}_{3} \mathrm{C}-\mathrm{O}\right)$ \\
\hline & & $1004(0.5)$ & $1004(0.1)$ & 1003 (32.9) & oop $(\mathrm{C}-\mathrm{H})\left(\mathrm{C}_{6} \mathrm{H}_{5}\right)$ \\
\hline $959 \mathrm{vw}$ & $958 \mathrm{vw}$ & $993(0.02)$ & $993(0.007)$ & $988(0.2)$ & oop $(\mathrm{C}-\mathrm{H})\left(\mathrm{C}_{6} \mathrm{H}_{5}\right)$ \\
\hline $933 \mathrm{vw}$ & $932 v w$ & $967(2.5)$ & $963(1.8)$ & $950(4.9)$ & $\rho\left(\mathrm{CH}_{2}\right)$ \\
\hline $895 w$ & $893 w$ & $946(3.0)$ & $946(2.8)$ & $938(3.6)$ & oop $(\mathrm{C}-\mathrm{H})\left(\mathrm{C}_{6} \mathrm{H}_{5}\right)$ \\
\hline \multirow[t]{2}{*}{$857 v w$} & $856 v w$ & $901(3.5)$ & $883(0.7)$ & $901(2.9)$ & $v(\mathrm{C} 1-\mathrm{C} 2)$ \\
\hline & & $862(0.01)$ & $862(0.02)$ & $857(0.3)$ & $\rho$ oop $(\mathrm{C}-\mathrm{H})\left(\mathrm{C}_{6} \mathrm{H}_{5}\right)$ \\
\hline $806 \mathrm{~m}$ & $804 s$ & $819(48.0)$ & $814(61.8)$ & $805(34.2)$ & $\delta(\mathrm{NN} 2 \mathrm{~N})$ \\
\hline $795 m$ & $794 m$ & $804(7.6)$ & $803(13.7)$ & $779(7.6)$ & oop $(\mathrm{NC} 5 \mathrm{~N})$ \\
\hline $734 s$ & $732 s$ & $745(42)$ & $745(42.7)$ & 749 (21.9) & oop (C5N4N3) \\
\hline $717 w$ & $717 w$ & $717(10.6)$ & $712(5.8)$ & $724(2.6)$ & oop $(\mathrm{NN} 2 \mathrm{~N})$ \\
\hline $697 \mathrm{~m}$ & $696 \mathrm{~m}$ & $705(33.1)$ & $705(34.4)$ & $709(45.5)$ & oop $(\mathrm{C}-\mathrm{H})\left(\mathrm{C}_{6} \mathrm{H}_{5}\right)$ \\
\hline $683 \mathrm{vw}$ & & $694(2.3)$ & $693(1.3)$ & $701(11.1)$ & $\delta(\mathrm{CCC})$ \\
\hline $677 w$ & $675 \mathrm{~m}$ & $680(13.5)$ & $662(13.8)$ & $688(4.9)$ & oop (NNN) \\
\hline 619vvw & & $633(0.05)$ & $633(0.04)$ & $631(0.01)$ & $\delta(\mathrm{CCC})$ \\
\hline $578 \mathrm{~m}$ & $576 \mathrm{~m}$ & $590(6.4)$ & $600(7.4)$ & $585(3.4)$ & $\rho\left(\mathrm{CH}_{2}\right)$ \\
\hline \multirow[t]{2}{*}{$505 w$} & $504 w$ & $514(4.6)$ & $514(4.6)$ & $541(11.7)$ & $\rho(C C C)$ \\
\hline & $484 \mathrm{vw}$ & $487(0.7)$ & $488(1.1)$ & 447 (1.9) & $\rho(C 1-C 2)$ \\
\hline
\end{tabular}

a Band intensities and shape: vs = very strong; $\mathrm{s}=$ strong; $\mathrm{m}=$ medium; $\mathrm{w}=$ weak; vw = very weak, sh: shoulder, br: broad.

b In parenthesis computed IR intensities in $\mathrm{Km} / \mathrm{mol}$ are given.

${ }^{c} v$ : stretching (subscripts s and as refer to symmetric and antisymmetric modes, respectively), $\delta$ : deformation, oop: out of plane deformation modes, $\rho$ : rocking mode.

and $\pi^{*}(\mathrm{~N} 1=\mathrm{C} 5)$ antibonding orbitals of the tetrazole group. In agreement with symmetry considerations, only this orbital can contribute to these out-of-plane interactions, the other lone pairs interacting solely through in-plane $\sigma$ interactions. For comparison, the NBO analysis has been also performed for the 1-tautomer. In this case the pure p-type lone pair is formally located at N1, with 


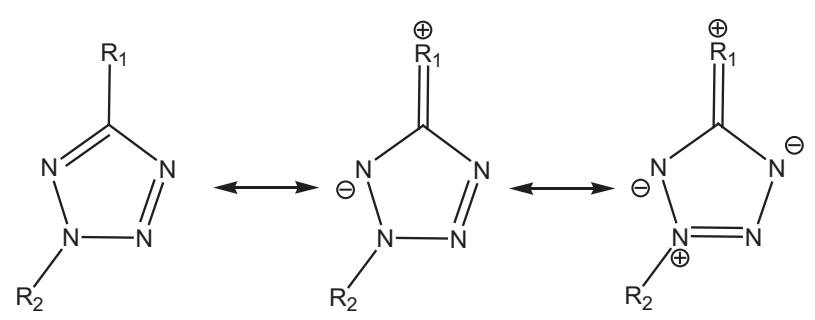

Scheme 2. Single and double excited resonance structure describing the electron donation by a donor substituent in 2-tetrazole (adapted from ref [40]). For the title species $\mathrm{R}_{1}=-\mathrm{C}_{6} \mathrm{H}_{5}$ and $\mathrm{R}_{2}=-\mathrm{CH}_{2} \mathrm{C}(\mathrm{O}) \mathrm{OCH}_{3}$.

Table 3

Selected $E^{(2)}$ donor-acceptor interactions [B3LYP/6-311++G(d,p), in kcal/mol] acting on the tetrazole moiety for different tautomeric and conformational forms of the title species.

\begin{tabular}{lllll}
\hline Donor $\rightarrow$ acceptor interaction & 2-Syn & 2-Anti & 1-Syn & 1-Anti \\
\hline $\operatorname{lp}(\mathrm{N} 4) \rightarrow \sigma^{*}(\mathrm{~N} 2=\mathrm{N} 3)$ & 7.33 & 7.34 & 6.15 & 6.10 \\
$\operatorname{lp}(\mathrm{N} 4) \rightarrow \sigma^{*}(\mathrm{~N} 1=\mathrm{C} 5)$ & 6.27 & 6.25 & 6.20 & 6.19 \\
$\operatorname{lp}(\mathrm{N} 3) \rightarrow \sigma^{*}(\mathrm{~N} 1=\mathrm{N} 2)$ & 8.07 & 8.10 & 7.73 & 7.82 \\
$\operatorname{lp}(\mathrm{N} 3) \rightarrow \sigma^{*}(\mathrm{~N} 4=\mathrm{C} 5)$ & 5.41 & 5.41 & 5.25 & 5.37 \\
$\operatorname{lp}(\mathrm{N} 2) \rightarrow \pi^{*}(\mathrm{~N} 3=\mathrm{N} 4)$ & 50.23 & 50.49 & 6.62 & 6.57 \\
$\operatorname{lp}(\mathrm{N} 2) \rightarrow \pi^{*}(\mathrm{~N} 1=\mathrm{C} 5)$ & 27.82 & 27.90 & 5.76 & 5.36 \\
$\operatorname{lp}(\mathrm{N} 1) \rightarrow \sigma^{*}(\mathrm{~N} 2=\mathrm{N} 3)$ & 8.53 & 8.60 & 38.04 & 38.43 \\
$\operatorname{lp}(\mathrm{N} 1) \rightarrow \sigma^{*}(\mathrm{~N} 4=\mathrm{C} 5)$ & 5.63 & 5.55 & 47.14 & 48.19 \\
\hline
\end{tabular}

similar electronic properties than that computed for the 2-tautomer. Selected donor-acceptor interactions for the syn and anti conformers of both tautomers are showed in Table 3.

For the 2-syn form, the computed $\operatorname{lp}_{\mathrm{p}}(\mathrm{N} 2) \rightarrow \pi^{*}(\mathrm{~N} 3=\mathrm{N} 4)$ and $\pi^{*}(\mathrm{~N} 1=\mathrm{C} 5)$ donor $\rightarrow$ acceptor interaction values are 50.23 and $27.82 \mathrm{kcal} / \mathrm{mol}$, respectively. For the 1 -syn tautomer, however, the relative energies of these interactions are inverted, with $E^{(2)}$ values of 38.04 and $47.14 \mathrm{kcal} / \mathrm{mol}$ for the $\operatorname{lp}_{\mathrm{p}}(\mathrm{N} 1) \rightarrow \pi^{*}(\mathrm{~N} 2=\mathrm{N} 3)$ and $\pi^{*}(\mathrm{~N} 4=\mathrm{C} 5)$, respectively. The close analysis of the off-diagonal NBO Fock matrix elements $\left(F_{i j}\right)$ and the energies of the interacting molecular orbitals $\left(\varepsilon_{j}-\varepsilon_{i}\right)$ shows that for the 2-tautomer a more efficient overlapping between the nitrogen lone pair and the $\pi^{*}(\mathrm{~N}=\mathrm{N})$ occurs, whereas the overlap is more efficient with $\pi^{*}(\mathrm{~N}=\mathrm{C})$ for the 1-tautomer. The strong electron donation into $\pi^{*}$ antibonding orbitals is reflected in the high electronic occupancy assigned to these "vacant" orbitals, of ca. 0.479 and 0.400 e, for the $\pi^{*}(\mathrm{~N} 3=\mathrm{N} 4)$ and $\pi^{*}(\mathrm{~N} 1=\mathrm{C} 5)$ of the 2 -syn form, respectively. It is interesting to notice that Matulis et al. [41] reported a similar value for $\operatorname{lp}_{\mathrm{p}}(\mathrm{N}) \rightarrow \pi^{*}(\mathrm{~N}=\mathrm{N})$ resonance interaction $(51.33 \mathrm{kcal} / \mathrm{mol})$ computed [B3LYP/6-31+G(d,p)] for the related 1-vinyl-5-amino1H-tetrazole.

Finally, as listed in Table 3, the negative hyperconjugation interactions, mainly characterized by electron donations from the $\operatorname{lp}(\mathrm{N})$ toward the vicinal $\sigma^{*}$ acceptors, are much lower in energy, with $E^{(2)}$ values computed between ca. 8 and $5 \mathrm{kcal} / \mathrm{mol}$.

\section{Conclusions}

In this work we clearly demonstrate that the base catalyzed esterification of 5-phenyl-2H-1,2,3,4-tetrazole with methyl 2-chloroacetate selectively gives the (5-phenyl-tetrazol-2-yl)acetic acid methyl ester tautomer. The structure was confirmed by single-crystal X-ray diffraction, showing that the phenyl and the tetrazole rings are almost co-planar, whiles the acetate group is perpendicular to the tetrazole moiety. Quantum chemical calculations at the B3LYP/6-311++G(d,p) level of approximation reproduces this experimental finding. Depending on the orientation of the $\mathrm{C}=\mathrm{O}$ double bond with respect to the tetrazole ring, two conformations are computed to be almost isoenergetic. Moreover, it is computed that the 2-tautomer is more stable than the 1 -tautomer by approximately $6 \mathrm{kcal} / \mathrm{mol}$.

The NBO population analysis reveal the relevance of the pure p-type $\left[\operatorname{lp}_{\mathrm{p}}(\mathrm{N} 2)\right]$ lone pair attached to the $\mathrm{N} 2$ nitrogen atom on the electronic structure of the tetrazole group. Computed $\operatorname{lp}_{\mathrm{p}}(\mathrm{N} 2) \rightarrow \pi^{*}(\mathrm{~N} 3=\mathrm{N} 4)$ and $\pi^{*}(\mathrm{~N} 1=\mathrm{C} 5)$ donor $\rightarrow$ acceptor interaction values for the most stable 2-syn form are 50.23 and $27.82 \mathrm{kcal} / \mathrm{mol}$, respectively. Thus, it is plausible that the interplay between steric effect and electronic interactions plays a relevant role on the tautomeric and conformational equilibria of substituted tetrazole species.

\section{Acknowledgments}

MFE is member of the Carrera del Investigador of CONICET (República Argentina). The Argentinean author thanks to the Consejo Nacional de Investigaciones Científicas y Técnicas (CONICET), the ANPCYT (PICT-2130) and to the Facultad de Ciencias Exactas, Universidad Nacional de La Plata for financial support.

\section{Appendix A. Supplementary data}

Supplementary data associated with this article can be found, in the online version, at http://dx.doi.org/10.1016/j.saa.2015.05.046.

\section{References}

[1] J. Roh, K. Vávrová, A. Hrabálek, Synthesis and functionalization of 5-substituted tetrazoles, Eur. J. Org. Chem. 2015 (2012) 6101-6118.

[2] G. Aromí, L.A. Barrios, O. Roubeau, P. Gamez, Triazoles and tetrazoles: prime ligands to generate remarkable coordination materials, Coord. Chem. Rev. 255 (2011) 485-546.

[3] J. Roh, K. Vávrová, A. Hrabálek, Synthesis and functionalization of 5-substituted tetrazoles, Eur. J. Org. Chem. 2012 (2012) 6101-6118.

[4] S. Berner, K. Mühlegger, H. Seliger, Studies on the role of tetrazole in the activation of phosphoramidites, Nucleic Acids Res. 17 (1989) 853-864.

[5] M. Malik, M. Wani, S. Al-Thabaiti, R. Shiekh, Tetrazoles as carboxylic acid isosteres: chemistry and biology, J. Incl. Phenom. Macrocycl. Chem. 78 (2014) 15-37.

[6] Z.P. Demko, K.B. Sharpless, Preparation of 5-substituted 1H-tetrazoles from nitriles in water, J. Org. Chem. 66 (2001) 7945-7950.

[7] M.A. Malik, S.A. Al-Thabaiti, M.A. Malik, Synthesis, structure optimization and antifungal screening of novel tetrazole ring bearing acyl-hydrazones, Int. J. Mol. Sci. 13 (2012) 10880-10898.

[8] S. Maione, E. Morera, I. Marabese, A. Ligresti, L. Luongo, G. Ortar, V. Di Marzo, Antinociceptive effects of tetrazole inhibitors of endocannabinoid inactivation: cannabinoid and non-cannabinoid receptor-mediated mechanisms, Br. J. Pharmacol. 155 (2008) 775-782.

[9] A. Rajasekaran, P.P. Thampi, Synthesis and analgesic evaluation of some 5-[î́2 (10-phenothiazinyl)ethyl]-1-(acyl)-1,2,3,4-tetrazoles, Eur. J. Med. Chem. 39 (2004) 273-279.

[10] X.-Y. Sun, C.-X. Wei, X.-Q. Deng, Z.-G. Sun, Z.-S. Quan, Evaluation of the anticonvulsant activity of 6-(4-chlorophenyoxy)-tetrazolo[5,1-a]phthalazine in various experimental seizure models in mice, Pharmacol. Rep. 62 (2010) 273-277.

[11] Y.L. Gao, G.L. Zhao, W. Liu, H. Shao, Y.L. Wang, W.R. Xu, L.D. Tang, J.W. Wang, Design, synthesis and in vivo hypoglycemic activity of tetrazole-bearing Nglycosides as SGLT2 inhibitors, Indian J. Chem. 49B (2010) 1499-1508.

[12] S.N. Rao, K.S. Babu, An improved and efficient synthesis of Irbesartan, an antihypertensive drug, Org. Commun. 4 (2011) 105-111.

[13] A.I. Lesnikovich, S.V. Levchik, A.I. Balabanovich, O.A. Ivashkevich, P.N. Gaponik, The thermal decomposition of tetrazoles, Thermochim. Acta 200 (1992) 427441.

[14] T.M. Klapötke, B. Krumm, F.A. Martin, J. Stierstorfer, New azidotetrazoles: structurally interesting and extremely sensitive, Chem. Asian J. 7 (2011) 214224.

[15] T.M. Klapötke, D.G. Piercey, 1,1'-Azobis(tetrazole): a highly energetic nitrogenrich compound with a N10 chain, Inorg. Chem. 50 (2011) 2732-2734.

[16] S.V. Voitekhovich, O.A. Ivashkevich, P.N. Gaponik, Synthesis, properties, and structure of tetrazoles: certain achievements and prospects, Russ. J. Org. Chem. 49 (2013) 635-654.

[17] D.M. Forkey, W.R. Carpenter, Mass spectrometry of methyltetrazoles, Org. Mass Spectrom. 2 (1969) 433-445.

[18] R.R. Fraser, K.E. Haque, Nuclear magnetic resonance and mass spectral properties of 5-aryltetrazoles, Can. J. Chem. 46 (1968) 2855-2859. 
[19] M. Pagacz-Kostrzewa, J. Krupa, M. Wierzejewska, Photochemical transformations of 5-methyltetrazole. Matrix isolation FTIR and DFT studies, J. Photochem. Photobiol. A Chem. 277 (2014) 37-44.

[20] A. Ismael, A. Gómez-Zavaglia, A. Borba, M.L.S. Cristiano, R. Fausto, Aminoimino tautomerization upon in vacuo sublimation of 2-methyltetrazolesaccharinate as probed by matrix isolation infrared spectroscopy, J. Phys. Chem. A 117 (2013) 3190-3197.

[21] V.G. Kiselev, P.B. Cheblakov, N.P. Gritsan, Tautomerism and thermal decomposition of tetrazole: high-level $a b$ initio study, J. Phys. Chem. A 115 (2011) 1743-1753.

[22] M. Daszkiewicz, M.K. Marchewka, 3-Amino-1,2,4-triazolium ion in [24(3at)]Cl and $[24(3 \mathrm{at})] 2 \mathrm{SnCl}_{6} \hat{\mathrm{A}} \cdot \mathrm{H}_{2} \mathrm{O}$. Comparative X-ray, vibrational and theoretical studies, Spectrochim. Acta 95A (2012) 204-212.

[23] A. Saeed, M. Hussain, M. Qasim, Novel N-acyl/aroyl-2-(5-phenyl-2H-tetrazol2-yl)acetohydrazides: synthesis and characterization, Turk. J. Chem. 38 (2014) 436-442.

[24] A.R. Katritzky, B.E.-D.M. El-Gendy, B. Draghici, C.D. Hall, P.J. Steel, NMR study of the tautomeric behavior of $\mathrm{N}$-(Ît-aminoalkyl)tetrazoles, J. Org. Chem. 75 (2010) 6468-6476.

[25] G. Sheldrick, A short history of SHELX, Acta Crystallogr. A 64 (2008) 112-122.

[26] M.J. Frisch, G.W. Trucks, H.B. Schlegel, G.E. Scuseria, M.A. Robb, J.R. Cheeseman, J.A. Montgomery Jr., T. Vreven, K.N. Kudin, J.C. Burant, J.M. Millam, S.S. Iyengar, J. Tomasi, V. Barone, B. Mennucci, M. Cossi, G. Scalmani, N. Rega, G.A. Petersson, H. Nakatsuji, M. Hada, M. Ehara, K. Toyota, R. Fukuda, J. Hasegawa, M. Ishida, T. Nakajima, Y. Honda, O. Kitao, H. Nakai, M. Klene, X. Li, J.E. Knox, H.P. Hratchian, J.B. Cross, C. Adamo, J. Jaramillo, R. Gomperts, R.E. Stratmann, O. Yazyev, A.J. Austin, R. Cammi, C. Pomelli, J.W. Ochterski, P.Y. Ayala, K. Morokuma, G.A. Voth, P. Salvador, J.J. Dannenberg, V.G. Zakrzewski, S. Dapprich, A.D. Daniels, M.C. Strain, O. Farkas, D.K. Malick, A.D. Rabuck, K. Raghavachari, J.B. Foresman, J.V. Ortiz, Q. Cui, A.G. Baboul, S. Clifford, J. Cioslowski, B.B. Stefanov, G. Liu, A. Liashenko, P. Piskorz, I. Komaromi, R.L. Martin, D.J. Fox, T. Keith, M.A. Al-Laham, C.Y. Peng, A. Nanayakkara, M. Challacombe, P.M.W. Gill, B. Johnson, W. Chen, M.W. Wong, C. Gonzalez, J.A. Pople, Gaussian 03, Gaussian Inc, Pittsburgh PA, 2003.

[27] M.J. Frisch, J.A. Pople, J.S. Binkley, Self-consistent molecular orbital methods 25. Supplementary functions for Gaussian basis sets, J. Chem. Phys. 80 (1984) 3265-3269.

[28] S. Saglam, A. Disli, Y. Erdogdu, M.K. Marchewka, N. Kanagathara, B. Bay, M.T. Güllüoğlu, Synthesis, characterization and theoretical studies of 5(benzylthio)-1-cylopentyl-1H-tetrazole, Spectrochim. Acta 135A (2015) 1011-1018.
[29] A. Fu, D. Du, Z. Zhou, Density functional theory study of vibrational spectra of acridine and phenazine, Spectrochim. Acta 59A (2003) 245-253.

[30] A.E. Reed, L.A. Curtiss, F. Weinhold, Intermolecular interactions from a natura bond orbital, donor-acceptor viewpoint, Chem. Rev. 88 (1988) 899-926.

[31] M. Pagacz-Kostrzewa, D. Jesariew, M. Podruczna, M. Wierzejewska, Infrared spectra and X-ray structure of (tetrazol-5-yl)acetic acid, Spectrochim. Acta 108A (2013) 229-235.

[32] M. Pagacz-Kostrzewa, J. Krupa, M. Wierzejewska, Carboxylic group and its tetrazolyl isostere in one molecule. Matrix isolation FTIR and DFT studies on thermal decomposition and photochemistry of (tetrazol-5-yl)acetic acid, J. Phys. Chem. A 118 (2014) 2072-2082.

[33] M.F. Erben, R. Boese, C.O. Della Védova, H. Oberhammer, H. Willner, Toward an intimate understanding of the structural properties and conformational preference of oxoesters and thioesters: gas and crystal structure and conformational analysis of dimethyl monothiocarbonate, $\mathrm{CH}_{3} \mathrm{OC}(\mathrm{O}) \mathrm{SCH}_{3}, \mathrm{~J}$. Org. Chem. 71 (2006) 616-622.

[34] F. Han, L. Yang, Z. Li, C. Xia, Acidic-functionalized ionic liquid as an efficient green and reusable catalyst for hetero-Michael addition of nitrogen, sulfur and oxygen nucleophiles to [small alpha],[small beta]-unsaturated ketones, Org. Biomol. Chem. 10 (2012) 346-354.

[35] Y. Li, L.-X. Gao, F.-S. Han, Efficient synthesis of 2,5-disubstituted tetrazolesvia the $\mathrm{Cu}_{2} \mathrm{O}$-catalyzed aerobic oxidative direct cross-coupling of $\mathrm{N}-\mathrm{H}$ free tetrazoles with boronic acids, Chem. Commun. 48 (2012) 2719-2721.

[36] R.E. Trifonov, I. Alkorta, V.A. Ostrovskii, J. Elguero, A theoretical study of the tautomerism and ionization of 5-substituted NH-tetrazoles, J. Mol. Struct. Theochem. 668 (2004) 123-132.

[37] I.N. Polyakova, V.V. Saraev, A.S. Gavrilov, E.L. Golod, Crystal and molecular structure of four adamantyl-substituted tetrazoles, Crystallogr. Rep. 54 (2009) 441-448.

[38] S.C.S. Bugalho, E.M.S. Macoas, M.L.S. Cristiano, R. Fausto, Low temperature matrix-isolation and solid state vibrational spectra of tetrazole, Phys. Chem. Chem. Phys. 3 (2001) 3541-3547.

[39] C. Araujo-Andrade, I. Reva, R. Fausto, Tetrazole acetic acid: tautomers, conformers, and isomerization, J. Chem. Phys. 140 (2014) 064306-064320.

[40] W.P. Oziminski, T.M. Krygowski, Comparison of the substituent effects in tetrazole systems and benzene. A computational study, Tetrahedron 67 (2011) 6316-6321.

[41] A.S. Lyakhov, V.E. Matulis, P.N. Gaponik, S.V. Voitekhovich, O.A. Ivashkevich, 1 Vinyl-5-amino-1H-tetrazole: X-ray molecular and crystal structures and quantum-chemical DFT calculations, J. Mol. Struct. 876 (2008) 260-267. 